\title{
MODELING OF AIR PERMEABILITY OF KNITTED FABRIC USING THE COMPUTATIONAL FLUID DYNAMICS
}

\author{
Adam K. Puszkarz, Izabella Krucińska
}

Lodz University of Technology, Department of Material and Commodity Sciences and Textile Metrology, 116 Zeromskiego Street, 90-924 Lodz, Poland Corresponding author: Adam K. Puszkarz; email: adam.puszkarz@.p.lodz.pl

\begin{abstract}
:
This article concerns the widespread matter of biophysical comfort. In this work, 10 double-layer knitted fabrics with potential application in multilayer garments addressed to a specific group of users, such as newborns, were investigated. The materials were constructed with the following raw materials: cotton, polypropylene, polyester, polyamide, bamboo, and viscose. The textiles with a comparable geometrical structure and different composition were tested for their air permeability. In the experimental part, the materials were tested in specific constant ambient conditions using an air permeability tester. In the simulation part, 3D models of actual textiles were designed and air permeability based on the performed simulations using finite volume method was calculated. Both measurements and simulations yielded comparable results and showed that the air permeability of the knitted fabric strongly depends on the thickness and geometrical parameters of yarn.
\end{abstract}

\section{Keywords:}

knitted fabric, simulation, air permeability, modeling, finite volume method

\section{Introduction}

Physiological comfort is the effect of many coefficients related to the human body, climatic conditions, environment, and clothing. The main role of clothing is to protect the body from the negative influence of external factors and its impact on the process of heat exchange between the human body and the environment. Heat transfer largely depends on the geometrical structure of the textile material as well as the thermal properties of the raw materials used to make the clothing. A clothing parameter that has a strong influence on the heat exchange between man and the environment is air permeability. Air permeability is one of the most important indicators of the value of textiles, especially for apparel fabrics, knitted fabrics, and technical fabrics, because this physical parameter determines the basic functions of the utility of these textiles, that is, the physiological properties of clothing textiles. In addition, air permeability describes the retaining ability for filtration materials.

In the recent years, many authors have conducted studies aimed at predicting the air permeability of textile materials based on their structural parameters. These studies typically involve knitted fabrics [1-4] or woven fabrics [5-13] used as technical products (i.e., filters) or barriers to protect the human body from the impact of small objects, such as microparticles or microorganisms. Some of the work is based primarily on the research in real textiles, but in a growing number of works, the main role of the experiment is to verify the theoretical mathematical models describing the relationship between the geometrical structure of textiles and their utility. Popular tools for understanding the physical processes occurring in textiles are the software that allows the precise designing of three-dimensional models of actual fabrics and performs virtual experiments using different computational methods such as the finite element method (FEM) or the computational fluid dynamics (CFD).

The present article is concerned with the air permeability of clothing as an important factor of physiological comfort. The air permeability of knitted fabrics depends primarily on geometry of the material (thickness of the individual layers and their mutual position), properties of yarn (cross-sectional shape and yarn length in a single loop, knitting pattern, and twist), and properties of fibers (fiber number in the yarn and fiber shape). All of these geometrical parameters result from the selection of a suitable raw material, technology of yarn production, and the production method of knitted fabric.

The main aim of this work is to design and apply 3D models (mapping geometrical parameters as mentioned earlier) of real knitted fabrics using specific CAD software (used in the science to study physical phenomena occurring in a wide range of materials, primarily solids, not only textiles) in order to predict their actual air permeability. The software was previously applied to build textile models and investigate their thermal properties presented in earlier papers [14-16]. In the current work, two models with varying degrees of mapping the geometry of yarn of 10 selected knitted fabrics of a very similar geometrical structure were created to prove which geometrical parameters of yarn and fibers are crucial in predicting air permeability. The research is first attempt to apply these models presented in the previous paper [14] to simulate air permeability. The reference point for the utility models was the experimental results performed on actual textiles. 


\section{Materials}

The subject of this work was textiles with potential applications in multilayer garments addressed to a specific group of users, such as newborns, which was previously studied in an earlier work. Investigations of thermal insulation were determined experimentally (by thermography) and from simulations carried out on three-dimensional models of actual textiles [14]. The examined materials were double-layer knitted fabrics with biophysical properties composed of two different plain loops connected by polyamide low-linear-density thread (66 22 dtex f7). Double-layer knitted fabrics (shown in Figure 1) was produced by means of double-bed circular knitting machine made by Mayer \& Cie in Germany (OVJA36 model; machine gauge, 20E; number of needles, $1872 \times 2$; cylinder diameter, 30"; number of feeders, 72). The thread does not form loops, and its percentage does not exceed $5 \%$ of mass per unit area of knitted fabric.

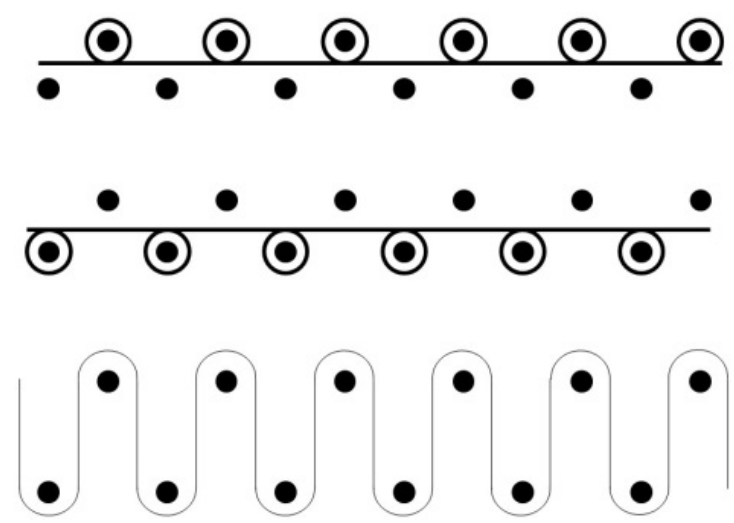

Figure 1. Scheme of structure of double-layer knitted fabric [19]

Lower layer of knitted fabric was made of conductive-diffusion threads (PP, PA, PET) that adhere directly to the body, and its purpose was to drain and transport moisture from the body both in the form of a liquid phase and a volatile one. Upper layer was made of sorptive threads (cotton, bamboo (viscose fibers made of regenerated cellulose from bamboo [17, 18]), and viscose), which is excluded from direct contact with the skin. The purpose of this layer was to keep the moisture away from the body and evaporate it to the environment. In the case of two knits, both layers were made of the same raw material (cotton and viscose). In Table 1, the physical parameters of the investigated materials are presented.

In Figure 2, optical microscopic images of double layer knitted fabric (No. 3 from Table 1) were presented.

\section{Methods}

\subsection{Experiment}

The aim of the experiment was to estimate the air permeability. The tests were conducted according to [23] in normal climate: relative humidity $(R H)=65 \%$, air temperature $\left(T_{\text {air }}\right)=20^{\circ} \mathrm{C}$, and air pressure $\left(p_{\text {air }}\right)=1,013.25 \mathrm{hPa}$. The studies were performed according to [24] by means of an air permeability tester, FX 3300 model made by Textest Instruments in Switzerland, which is shown in Figure 3.

During the measurement of air permeability, the sample is positioned flat and motionless above an opening to the reservoir with air at a pressure that was $100 \mathrm{~Pa}$ less than the normal pressure. As a result of the constant pressure difference (maintained by the measuring device), air flow through the knitted fabric is perpendicular to its surface. The device measures the velocity of air leaving the textile. The air permeability of each knitted fabric was determined as the average of 10 independent measurements at a pressure difference of $100 \mathrm{~Pa}$. The surface area of the sample was $20 \mathrm{~cm}^{2}$. The measurements were made for two sides of the sample: lower layer (layer of the clothing directed to skin of the human) and upper layer (directed to the surrounding) of the knitted fabric.

\subsection{Model design}

For the theoretical analysis of the air permeability of textiles tested experimentally, a 3D model for each knitted fabric was designed in SolidWorks 2014 software based on the stereoscopic optical microscopic images (Figure 4). These models differed in the precision of mapping yarn.
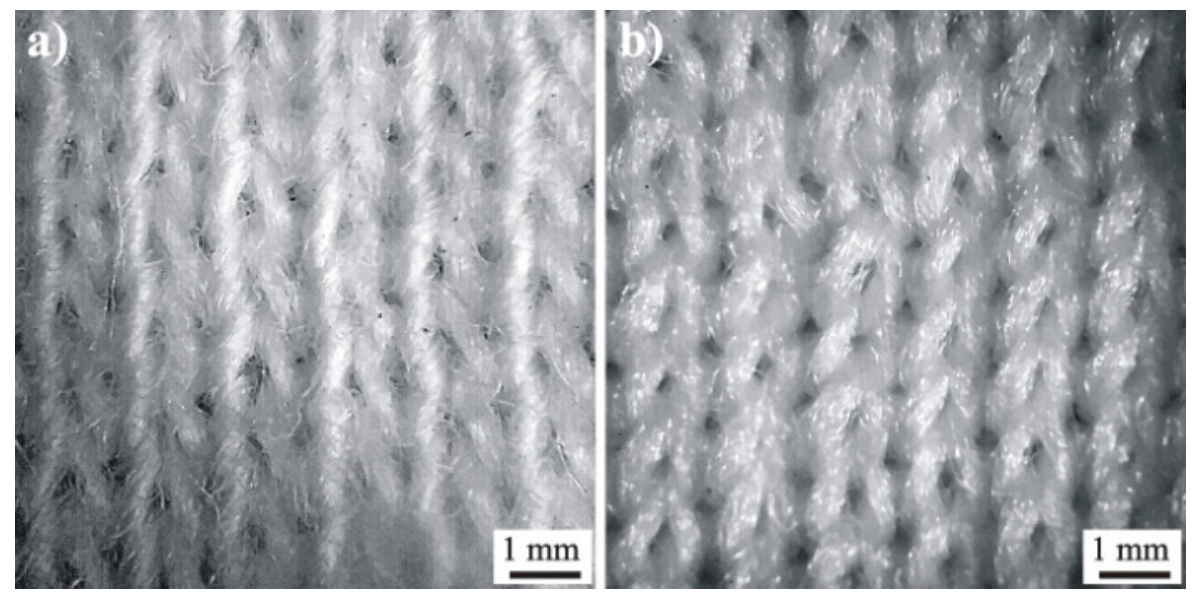

Figure 2. Optical microscopic images of double layer knitted fabric (No. 3 from Table 1): (a) upper layer made of cotton; (b) lower layer made of PET. 


\begin{tabular}{|c|c|c|c|c|c|c|c|c|c|c|c|}
\hline \multirow{2}{*}{ 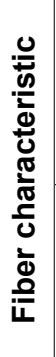 } & 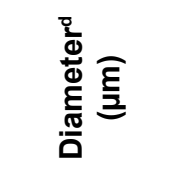 & 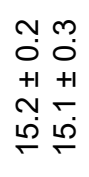 & 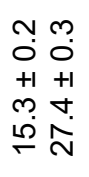 & 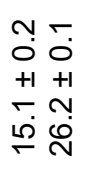 & 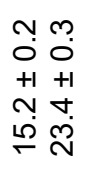 & \begin{tabular}{ll}
\multirow{2}{*}{} & $m$ \\
0 & 0 \\
+1 & +1 \\
+ & 0 \\
$\dot{N}$ & $\stackrel{\sim}{N}$
\end{tabular} & 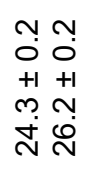 & 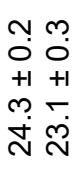 & 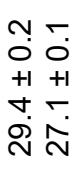 & 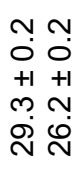 & 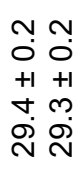 \\
\hline & $\frac{\text { ò }}{\frac{\delta}{\delta}}$ & $\begin{array}{l}100 \\
+1+1 \\
\stackrel{+1}{N} \underset{N}{\sim}\end{array}$ & 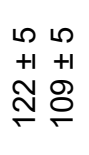 & 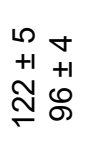 & 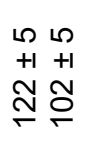 & $\begin{array}{l}+10 \\
+1+1 \\
+1 \\
\infty \\
\infty\end{array}$ & $\begin{array}{ll}+ & 0 \\
+1 & +1 \\
0 & 8 \\
\infty & 8\end{array}$ & $\begin{array}{l}+5 \\
+1 \\
+1 \\
\infty \\
\infty \\
\infty\end{array}$ & $\begin{array}{l}+5 \\
+1 \\
+1 \\
\infty \\
\infty\end{array}$ & $\begin{array}{ll}5 & 0 \\
+1 & +1 \\
1 & 8 \\
\infty & 8\end{array}$ & $\begin{array}{l}+ \\
+1+1 \\
+\infty \\
\infty\end{array}$ \\
\hline \multirow{5}{*}{ 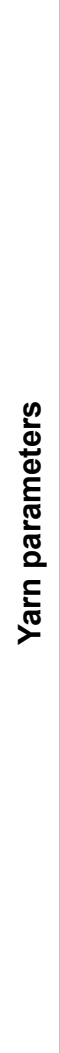 } & 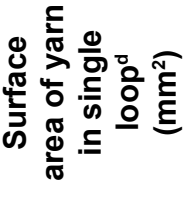 & 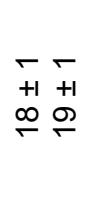 & $\begin{array}{l}\mp \sim \\
+++1 \\
\infty \\
\sim\end{array}$ & $\begin{array}{l}-+ \\
++1 \\
\stackrel{+}{+} \stackrel{\sim}{\circ}\end{array}$ & $\begin{array}{l}\mathbb{N}- \\
++1 \\
\infty \\
\infty\end{array}$ & $\begin{array}{l}\sim \stackrel{\sim}{\sim} \\
\stackrel{+1}{\sim} \stackrel{\sim}{\sim}\end{array}$ & $\begin{array}{l}\ulcorner\sim \\
++1 \\
\sim \\
\sim\end{array}$ & 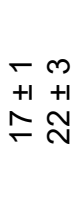 & 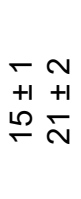 & 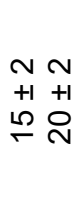 & 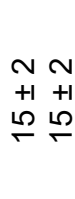 \\
\hline & 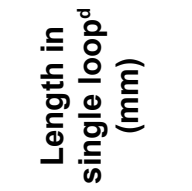 & 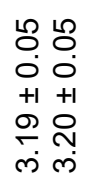 & 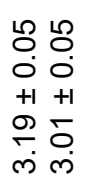 & 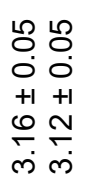 & 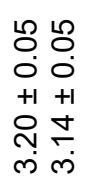 & 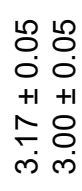 & 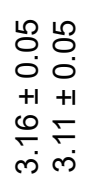 & 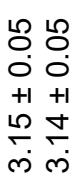 & $\begin{array}{ll}2 & 2 \\
0 & 0 \\
0 & 0 \\
+1 & +1 \\
8 & 0 \\
0 & 0 \\
\dot{m} & \dot{m}\end{array}$ & 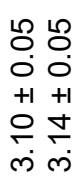 & 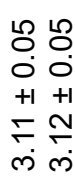 \\
\hline & 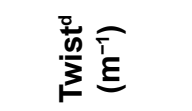 & 옷오 & ஜ్రిం & $L_{\infty}^{\infty} \circ$ & $\stackrel{1}{\infty} 0$ & స̃o & ণัo & సুo & 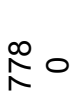 & $\stackrel{\infty}{N} \circ$ & $\stackrel{\infty}{\stackrel{\infty}{\wedge}} \stackrel{\infty}{\wedge}$ \\
\hline & 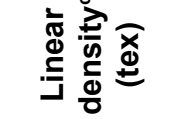 & ని & $\stackrel{\sim}{\infty} \infty$ & 뇬 & 尺 & $\stackrel{\sim}{\infty}$ & 요 $\stackrel{2}{\square}$ & $\stackrel{\sim}{\nabla}$ & $\stackrel{\sim}{\infty} \infty$ & 욘 & ని న \\
\hline & 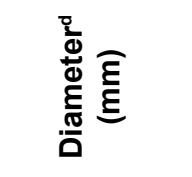 & $\begin{array}{ll}5 & 5 \\
0 & 0 \\
0 & 0 \\
+1 & +1 \\
1 & 0 \\
N & 0 \\
0 & 0\end{array}$ & 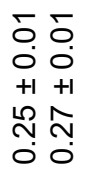 & $\begin{array}{ll}5 & - \\
0 & 0 \\
0 & 0 \\
+1 & +1 \\
0 & 0 \\
N & 0 \\
0 & 0\end{array}$ & 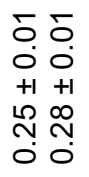 & \begin{tabular}{ll}
5 & 5 \\
0 & 0 \\
0 \\
+1 & +1 \\
N̦ & \multirow{N}{0}{} \\
0 & 0
\end{tabular} & 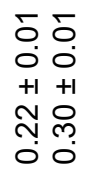 & 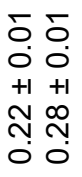 & 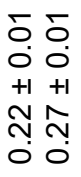 & $\begin{array}{ll}5 & 5 \\
0 & 0 \\
0 & 0 \\
+1 & +1 \\
\text { No } & 0 \\
0 & 0 \\
0 & 0\end{array}$ & 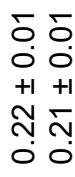 \\
\hline \multirow{4}{*}{ 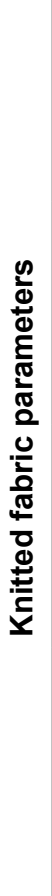 } & 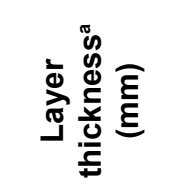 & $\begin{array}{ll}5 & 5 \\
0 & 0 \\
0 & 0 \\
+1 & +1 \\
0 & 0 \\
0 & 0 \\
0 & 0\end{array}$ & $\begin{array}{ll}5 & 5 \\
0 & 0 \\
0 & 0 \\
+1 & +1 \\
2 & 0 \\
& 0 \\
0 & 0\end{array}$ & $\begin{array}{ll}5 & 5 \\
0 & 0 \\
0 & 0 \\
+1 & +1 \\
1 & 8 \\
& 0 \\
0 & 0\end{array}$ & $\begin{array}{ll}5 & 5 \\
0 & 0 \\
0 & 0 \\
+1 & +1 \\
0 & 0 \\
0 & 0 \\
0 & 0\end{array}$ & $\begin{array}{ll} & 5 \\
0 & 0 \\
0 & 0 \\
+1 & +1 \\
N & 0 \\
0 & 0 \\
0 & 0\end{array}$ & $\begin{array}{ll}5 & 5 \\
0 & 0 \\
0 & 0 \\
+1 & +1 \\
\kappa & 0 \\
\hat{T} & 0 \\
0 & 0\end{array}$ & $\begin{array}{ll}5 & 5 \\
0 & 0 \\
0 & 0 \\
+1 & +1 \\
0 & 0 \\
0 & 10 \\
0 & 0 \\
0\end{array}$ & 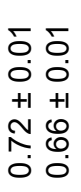 & $\begin{array}{ll}5 & 5 \\
0 & 0 \\
0 & 0 \\
+1 & +1 \\
1 & 0 \\
0 & 0 \\
0 & 0\end{array}$ & 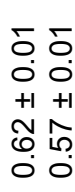 \\
\hline & 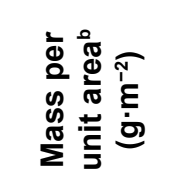 & $\begin{array}{l}\stackrel{\oplus}{+} \\
\stackrel{+1}{N} \\
\stackrel{\sim}{\sim}\end{array}$ & $\begin{array}{l} \pm \\
+1 \\
\stackrel{N}{0}\end{array}$ & $\begin{array}{l}\frac{1}{2} \\
+1 \\
\text { N }\end{array}$ & $\begin{array}{l}\stackrel{N}{+} \\
\stackrel{+1}{\sim} \\
\stackrel{\infty}{\leftarrow}\end{array}$ & $\begin{array}{l}\stackrel{\varphi}{+} \\
+1 \\
0 \\
\stackrel{N}{N}\end{array}$ & $\begin{array}{l}\stackrel{6}{\infty} \\
+1 \\
\stackrel{N}{N}\end{array}$ & $\begin{array}{l}\stackrel{m}{+} \\
+1 \\
\stackrel{2}{\sigma} \\
\stackrel{5}{\sigma}\end{array}$ & $\begin{array}{l}\mathscr{0} \\
+1 \\
0 \\
\stackrel{D}{N}\end{array}$ & $\begin{array}{l}\frac{10}{++1} \\
\frac{+1}{N}\end{array}$ & $\begin{array}{l}\stackrel{0}{1} \\
+1 \\
\infty \\
\sim \\
N\end{array}$ \\
\hline & 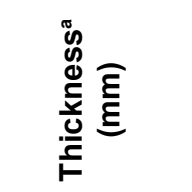 & 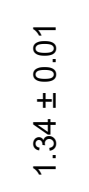 & $\begin{array}{l}5 \\
0 \\
0 \\
+1 \\
o \\
+ \\
+\end{array}$ & 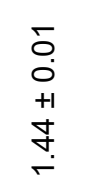 & $\begin{array}{l}\tilde{o} \\
0 \\
+1 \\
0 \\
\stackrel{p}{r}\end{array}$ & $\begin{array}{l}\bar{\delta} \\
\dot{0} \\
+1 \\
\stackrel{+}{\rho} \\
\stackrel{m}{-}\end{array}$ & $\begin{array}{l}\tilde{\sigma} \\
0 \\
+1 \\
0 \\
m \\
\end{array}$ & $\begin{array}{l}5 \\
0 \\
+1 \\
0 \\
\vdots \\
\leftarrow\end{array}$ & $\begin{array}{l}\tilde{0} \\
0 \\
+1 \\
\infty \\
\infty \\
\stackrel{p}{r}\end{array}$ & $\begin{array}{l}\bar{o} \\
\dot{0} \\
+1 \\
\stackrel{1}{N} \\
\stackrel{+}{-}\end{array}$ & $\begin{array}{l}5 \\
0 \\
0 \\
+1 \\
0 \\
\stackrel{+}{-}\end{array}$ \\
\hline & 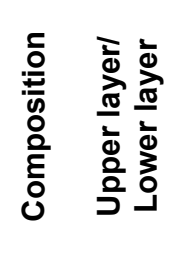 & 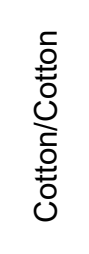 & 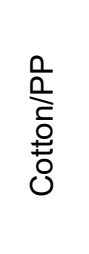 & 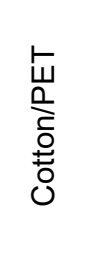 & 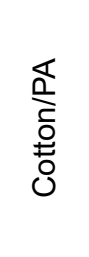 & $\begin{array}{l}\frac{0}{0} \\
\frac{0}{8} \\
\frac{0}{\circ} \\
\frac{0}{\sigma} \\
\infty\end{array}$ & 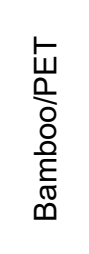 & 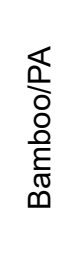 & 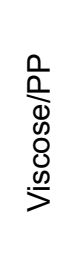 & 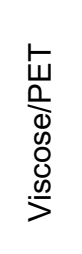 & 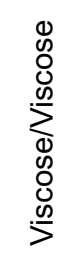 \\
\hline & zo & - & $\sim$ & $m$ & $\nabla$ & 10 & 0 & $\Lambda$ & $\infty$ & $\sigma$ & 으 \\
\hline
\end{tabular}




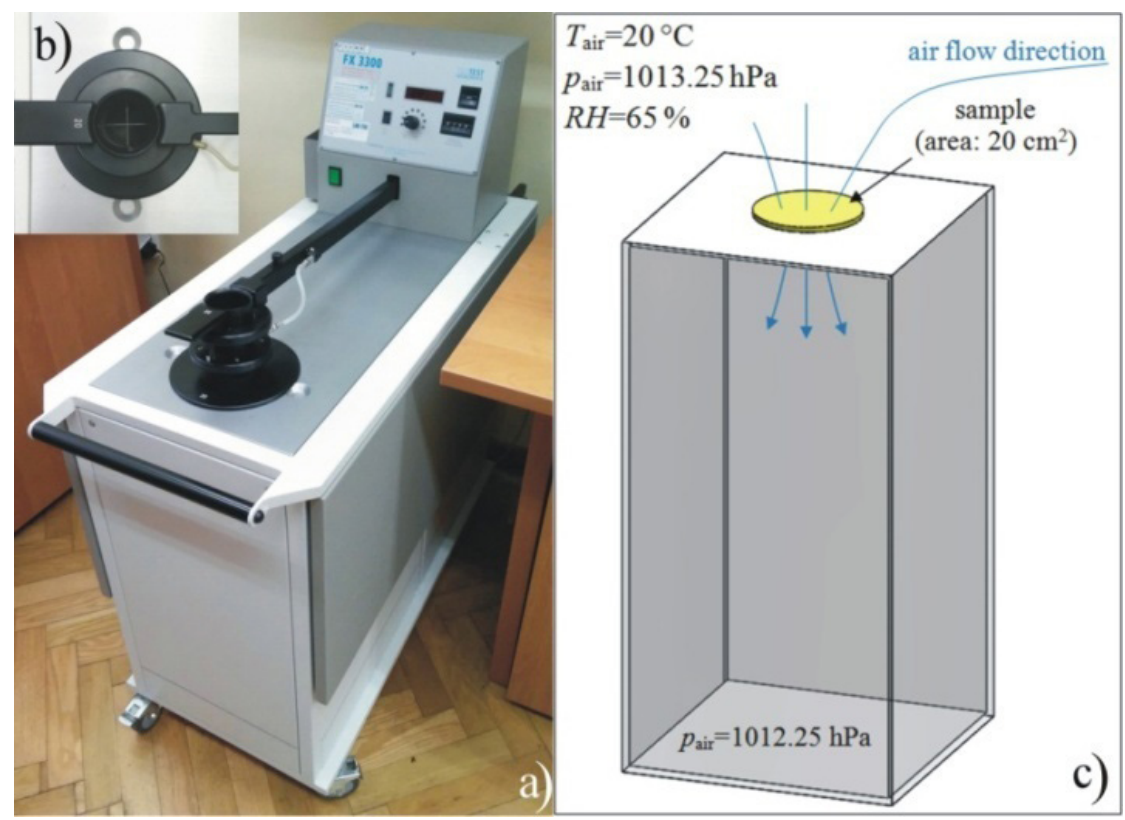

Figure 3. The view of set up for the measurement of air permeability: (a) air permeability tester (FX 3300 model), (b) round place on the sample with an area of $20 \mathrm{~cm}^{2}$ (top view), and (c) scheme of the air permeability measurement system.
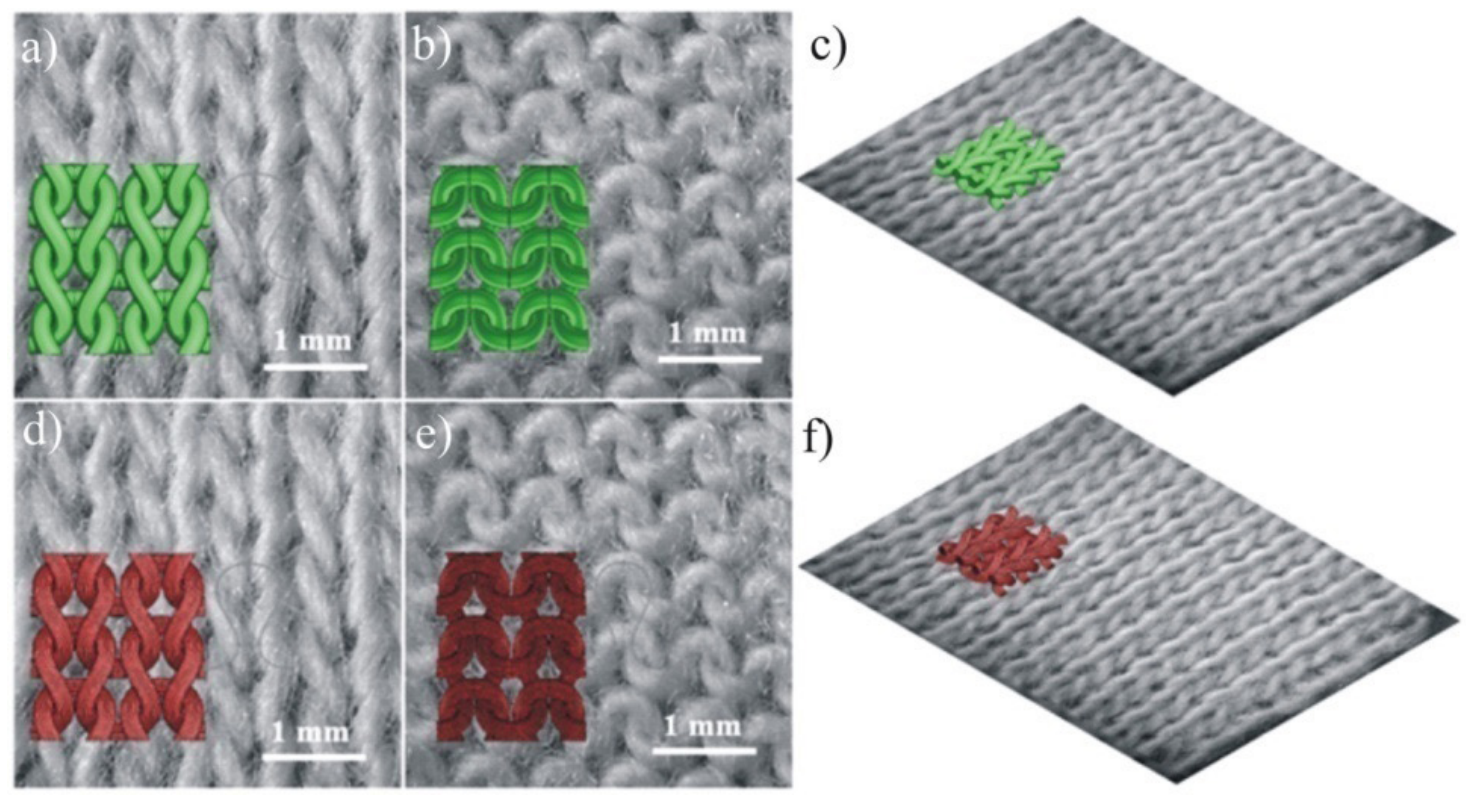

Figure 4. Monofiber model $(a-c)$ and multifiber model $(d-f)$ created based on the stereoscopic optical microscopic images.

First, the highly simplified model (the so-called monofiber model) did not take into account the individual fibers (i.e., the yarn as a single-component, continuous object similar to that in monofilament). However, it reproduced differences in the following physical parameters of the textiles: (1) thickness of the knitted fabric, (2) yarn length in single loop, and (3) yarn diameter (equivalent diameter, because the actual yarns did not have a circular cross section). The second model (the so-called multifiber model) took into account the same three physical parameters of the textiles from the monofiber model. However, it also reproduced the internal structure of the yarn, including fiber shape: (4) fiber length in single loop, (5) fiber diameter, (6) fiber number, (7) specific surface area of yarn, and (8) yarn twist. A comparison of the two models is shown in Figure 5. In the multifiber model, the diameter of the fibers was intentionally increased in relation to the real sizes (Table 1) in order to improve readability of the scheme.

The fiber length in a single loop was approximately equal to the yarn length because the twist per loop length (approximately $3 \mathrm{~mm}$ ) did not exceed 1. In both the models, the knitted fabric thickness, layer thickness, yarn diameter, and yarn length in a single loop for each material were the same (all according to Table 1). Both the monofiber model and multifiber model did not include a single polyamide thread connecting the two layers because it had a negligible mass compared to the mass of knitted fabric and its influence on the air flow through the textile was small. Both geometrical models have been attributed to raw materials from Table 1 , as they have no impact on the simulation results of air flow through the textiles. The 
average values of the following physical parameters, as given in Table 1, were experimentally measured according to relevant standards: knitted fabric thickness, single layer thickness [19], and mass per unit area [20]. Yarn twist was determined based on the known values, including the linear density of the yarn and the metric twist factor, $\alpha_{\mathrm{m}}$. The yarn length in a single loop was estimated based on stereoscopic optical microscopic images (yarn equivalent diameter, fiber number, and fiber diameter were measured based on the scanning electron microscopic images of yarn cross section) using ImageJ software and were mapped into the design of the 3D models. The specific surface area of yarn was calculated based on the known fiber number. In both the models, the circular cross section of the yarn, as well as the circular cross section of the fiber in the multifiber model, was assumed. In the case of cotton fibers, the equivalent diameter was used because of its cross section (the cross sections of other chemical fibers were circular).
The first step in the design of each model was to create a twodimensional sketch of the axis of a single loop on the plane using non-uniform rational basis spline (NURBS) curves. The shape of the curve was specified by the average sizes of the loop using actual material, for example, for cotton, the height is $1.10 \mathrm{~mm}$ and the width is $0.91 \mathrm{~mm}$ (Figure 6a).

The next step was to draw a sketch describing the profile of the loop in a plane perpendicular to the previous one (Figure $6 b)$. Applying the projection operation of the first sketch to the profile, a three-dimensional axis of the loop was obtained (Figure 6c). The next step of the design was to construct a cross-sectional sketch of the yarn built of individual fibers (Figure 6d). The final shape of the loop was obtained using a swept boss/base operation performed on the objects gained in the last two steps (Figure 6e).
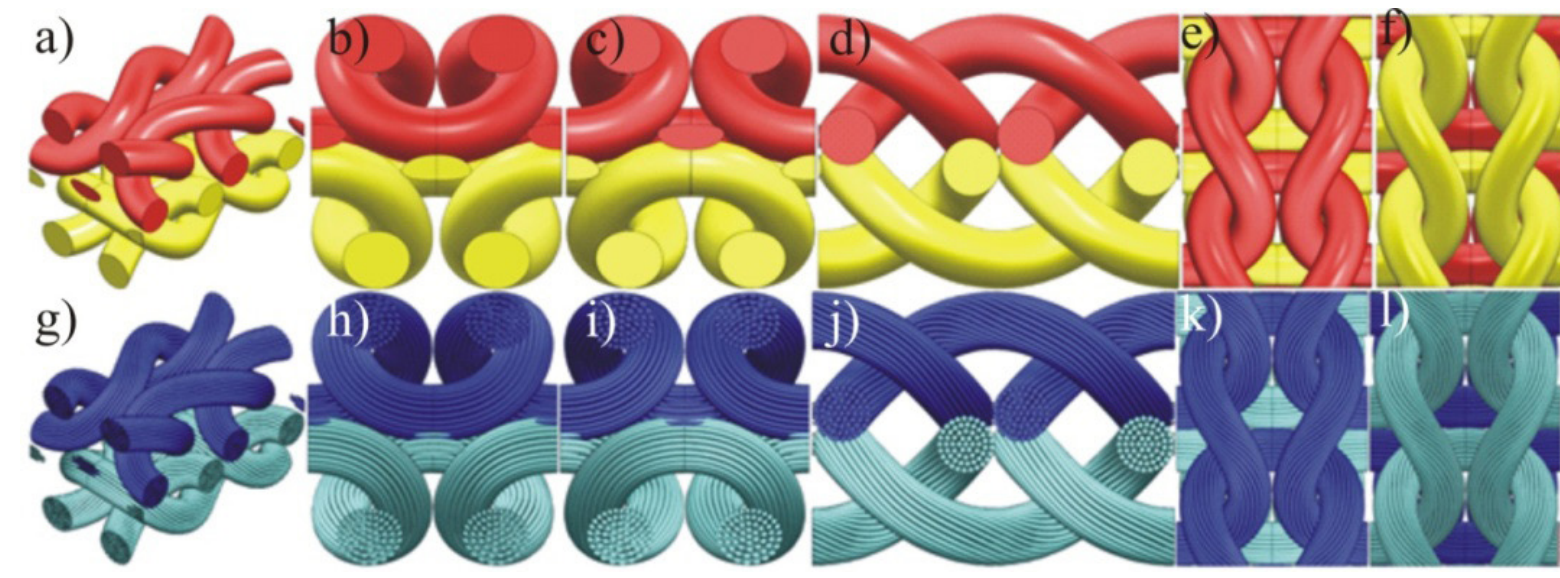

Figure 5. Comparison of monofiber model $(a-f)$ and multifiber model $(g-l)$ for double layer knitted fabric (in multifiber model, the diameter of the fibers was intentionally increased in relation to the real sizes (Table 1) in order to improve readability of the scheme) [14].

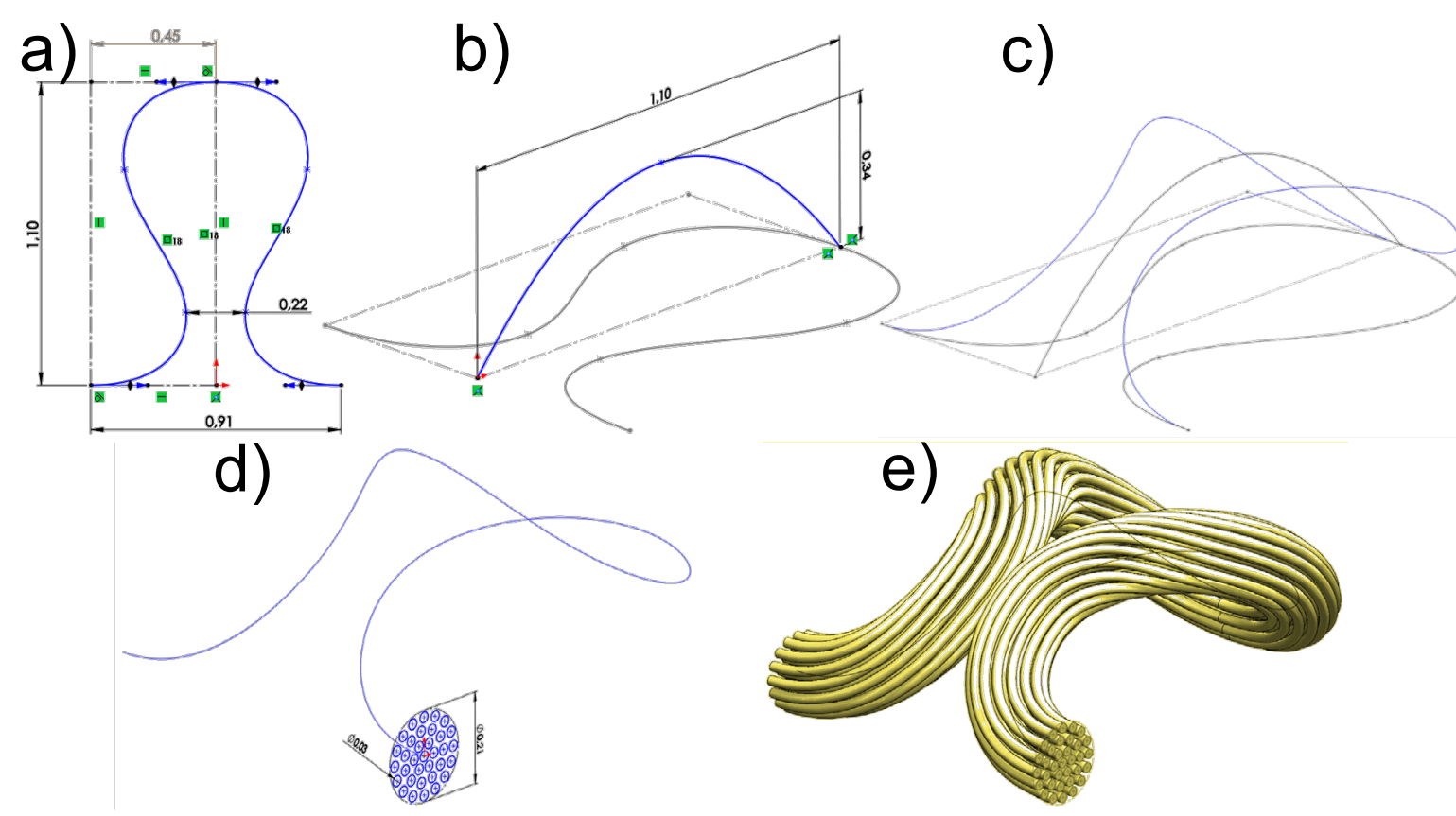

Figure 6. Stages of designing the 3D multifiber model of a single loop (the diameter of the fibers was intentionally increased in relation to the real sizes (Table 1) in order to improve readability of the scheme) [14]. 


\subsection{Simulations}

\subsubsection{Equations describing the fluid flow}

SolidWorks Flow Simulation using CFD analysis makes possible to predict both laminar and turbulent flows. Laminar flows are present at low values of the Reynolds number, which is defined as the product of representative scales of velocity and length divided by the kinematic viscosity. In case when the Reynolds number exceeds a certain critical value, the flow becomes turbulent, that is, flow parameters, start to fluctuate randomly [25].

The instantaneous continuity equation (1), momentum equation (2), and energy equation (3) for a compressible fluid can be expressed as [25]

$$
\begin{aligned}
& \frac{\partial \rho}{\partial t}+\frac{\partial}{\partial x_{i}}\left(\rho v_{i}\right)=0 \\
& \frac{\partial}{\partial t}\left(\rho v_{i}\right)+\frac{\partial}{\partial x_{j}}\left(\rho v_{i} v_{j}+p \delta_{j}-\tau_{j}\right)=
\end{aligned}
$$

where $i$ and $j$ are spatial components and take the values 1 , 2, 3,

$$
\frac{\partial}{\partial t}\left[\rho\left(e+\frac{1}{2} v_{i} v_{i}\right)\right]+\frac{\partial}{\partial x_{j}}\left[\rho v_{j}\left(h+\frac{1}{2} v_{i} v_{i}\right)\right]-\frac{\partial}{\partial x_{j}} v_{j} \tau_{j}+\frac{\partial q_{j}}{\partial x_{j}}=0
$$

where $r$ is the fluid density, $t$ is the time, $x$ is the fluid position, $e$ is the specific internal energy, $v$ is the fluid velocity,

$$
h=e+\frac{p}{\rho}
$$

is the specific enthalpy, $\mathrm{T}_{i j}$ is the stress tensor, $q_{j}$ is the heat flux vector, and $p$ is the pressure. For compressible flow, $T_{i j}$ is given by

$$
\tau_{i j}=2 \mu\left(s_{j}-\frac{1}{3} \frac{\partial v_{k}}{\partial x_{k}} \delta_{j}\right),
$$

where the strain-rate tensor $s_{i j}$ is given by

$$
s_{i j}=\frac{1}{2}\left(\frac{\partial v_{i}}{\partial x_{j}}+\frac{\partial v_{j}}{\partial x_{i}}\right) .
$$

The conductive heat-flux $q_{i}$ is given by Fourier's law:

$$
q_{j}=-\lambda \frac{\partial T}{\partial x_{j}}
$$

where $\lambda$ is the thermal conductivity and $T$ is the temperature. It is not possible to solve the instantaneous equations (1-3) directly for most engineering applications [25].
Here, simulations were performed for one-dimensional air flow in which the velocity depends primarily on one dimension (perpendicular to the layers of knitted fabric). Let us consider the volume of fluid entering and exiting from the volume reduced by cross sections $A$ and $A+\frac{\partial A}{\partial S}$ in time $d t$ (Figure 7) [26]. The $d S$ is distance from cross section $A$ to cross section $A+\frac{\partial A}{\partial S}$.

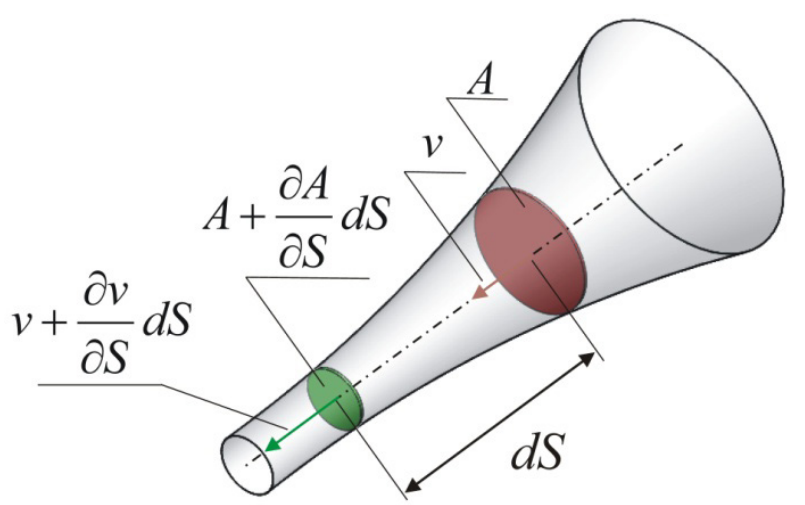

Figure 7. Scheme of fluid flow inside a tube of a variable cross section (according to [26])

The mass of the fluid flowing through section $A$ at a velocity $v$ in time $d t$ is $\rho v A d t$, while the mass of the fluid flowing out at a velocity $v+\frac{\partial v}{\partial S} d S$ through section $A+\frac{\partial A}{\partial S} d S$ at the same time is $\left(\rho+\frac{\partial \rho}{\partial S} d S\right)\left(A+\frac{\partial A}{\partial S} d S\right)\left(v+\frac{\partial v}{\partial S} d S\right) d t$.

The mass difference of fluid entering and exiting from the element is equal to the mass gain in time $d t$ :

$$
\rho A v d t-\left(\rho+\frac{\partial \rho}{\partial S} d S\right)\left(A+\frac{\partial A}{\partial S} d S\right)\left(v+\frac{\partial v}{\partial S} d S\right) d t=\frac{\partial \rho}{d t} d t A d s .
$$

After the transformation, equation 8 takes the form

$$
A \frac{\partial \rho}{d t}+\frac{\partial(\rho A v)}{\partial S}=0
$$

For an incompressible fluid ( $r=$ const), equation 9 takes the form

$$
A \frac{\partial \rho}{d t}+\frac{\partial(\rho A v)}{\partial S}=0
$$

Equation (9) can also be written as

$$
A \frac{\partial \rho}{d t}+\frac{\partial(\rho v)}{\partial S}+\rho v \frac{\partial A}{\partial S}=0 .
$$

In the case of steady flow (parameters do not depend on time), equations 10 and 11 are transformed into the following:

$$
\rho A v=\text { const }(\text { for a compressible fluid) }
$$

and

$$
A v=\text { const } \quad \text { (for an incompressible fluid). }
$$

Sometimes gases can also be considered to be incompressible fluids, namely, when the gas flows with a small and moderate velocity relative to the velocity of sound $\left(340.3 \mathrm{~m} \cdot \mathrm{s}^{-1}\right)$. In this case, the pressure changes are small in relation to the average value, while the volume change and the density change are so 
small that they are usually omitted. As the Reynolds numbers typically present in real cases, these equations have very chaotic turbulent solutions and it is necessary to model the influence of the smallest scales. Most turbulence models are based on one-point averaging of the instantaneous equations. To predict turbulent flows, SolidWorks software uses the Favre-averaged Navier-Stokes equations, in which timeaveraged effects of the flow turbulence on the flow parameters are considered, while the other large-scale, time-dependent phenomena are taken into account directly. On the basis of this procedure, extra terms known as the Reynolds stresses appear in the equations and additional information must be provided. To close this system of equations, flow simulation uses transport equations for the turbulent kinetic energy and its dissipation rate from the so-called $k$-e model [25].

\subsubsection{Conditions of air flow simulations}

Theoretical calculations of air permeability were carried out by means of simulating actual experiment conditions as schematically shown in Figure 8 . Owing to the periodic structure of the knitted fabric, the models were reduced to the smallest repetitive element and were placed in the midheight of the rectangular channel. The channel height was 10 $\mathrm{mm}$, while the sidewalls were tangential to the model and their dimensions were aligned with the model of the particular fabric. To eliminate the effects of asymmetric boundary conditions, settings were applied to imitate an infinite layer of knitted fabric propagating outside of the domain in all four directions in the horizontal plane. The values of air pressure $p_{\text {air }}$ on both sides of the channel were identical to the experiment (1013.25 and $1012.25 \mathrm{~Pa})$. As a result, a pressure difference $\Delta p_{\text {air }}(100 \mathrm{~Pa})$ forced air flow along the channel, through the model of the textile. For these conditions, the average air velocity in the channel did not exceed $2 \mathrm{~m} \cdot \mathrm{s}^{-1}$. The Reynolds number $(R e)$ was within the range of $288-1,220$ for the monofiber model and within the range of 308-1,240 for the multifiber model, so for all knitted fabric models, the flow was laminar $(R e<2,300)$ [26]. All simulations were performed in the steady state (air flow was independent of time) according to the experimental measurements described in Section 3.1.

Before the calculations, the software divided the computational domain (containing the model of knitted fabric and the air inside the channel) into tens of thousands of cells (from 43,234 to 65,118 in the multifiber model and from 34,502 to 22,907 in the monofiber model). The fluid cells were filled with air, whereas the partial cells contained both knitted fabric and air. The number of cells was dependent on the number, shape, and size of the elements making up the model of the particular knitted fabric. A much larger number of cells in the multifiber model in comparison to the monofiber model were mainly due to the mapping of the individual fibers.

In Table 2, the number of cells in each model in relation to the geometrical parameters of the yarns and fibers is presented. For both the models (monofiber and multifiber), for each of the 10 knitted fabrics, several test simulations were performed to verify the dependence between the accuracy of the results and the finite volume mesh density. Further increase in the number

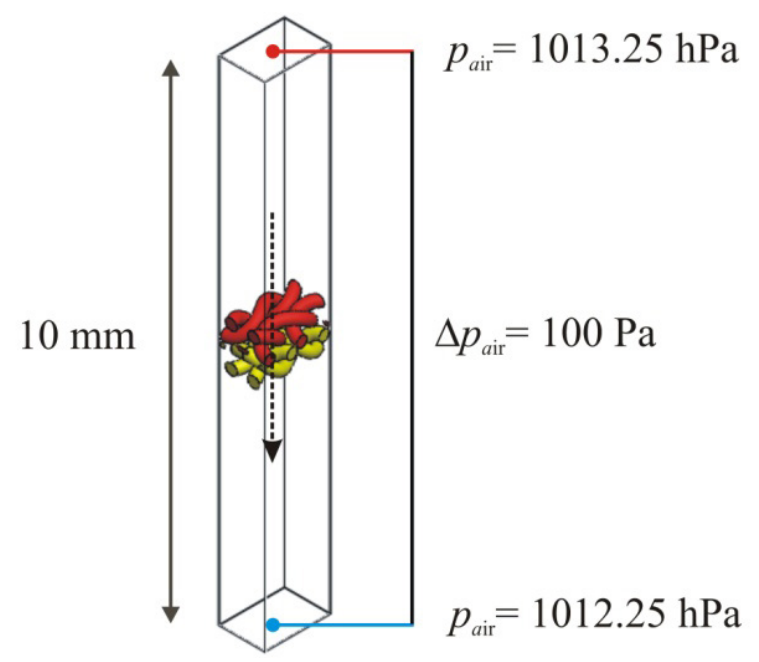

Figure 8. Simulation conditions for calculating the air permeability of knitted fabrics (dashed line indicates the direction of the air flow)

of cells did not significantly affect the precision of all calculated parameters presented in Figure 12.

\section{Results and comments}

The main objective of the performed simulations was to calculate the average velocity of air leaving the textile model in order to compare it with that measured in the experiment. For this purpose, the air velocity distribution for each knitted fabric was obtained on a horizontal plane located directly below the fabric model as presented in Figure 9b (monofiber model) and Figure 10b (multifiber model). In both the distributions, as expected, the areas with the highest air velocity are inside the loop where the air can flow freely.

For comparison, the distributions of air velocity on a horizontal plane placed directly over the model were determined as presented in Figure 9a (monofiber model) and Figure 10a (multifiber model). These distributions are very similar to the shape of areas with comparable values. However, on the top plane (Figures 9a and 10a), the air velocity is much higher than in the lower one (Figures $9 \mathrm{~b}$ and 10b) because at this height, the air flow has not slowed down yet as a result of a collision with knitted fabric.

By comparing the distributions on the respective planes, one can clearly observe the higher values of air velocity for the multifiber model, which may be a result of the presence of free spaces between the individual fibers, forming an additional path for air flow in which the air accelerates due to a narrow space.

The most significant analyzed parameter affecting the air permeability was optical porosity, defined as the area not covered by the material in the direction perpendicular to the layer. The optical porosity was determined by digital image analysis using the program ImageJ.

Because of the construction of a double layer knitted fabric (wherein the loops are not located directly above each other 
Table 2. Cell number in each model in relation to the geometrical parameters of the yarns and fibers

\begin{tabular}{|c|c|c|c|c|c|c|c|c|c|c|}
\hline \multirow{3}{*}{ No } & \multirow{3}{*}{$\begin{array}{l}\text { Knitted } \\
\text { fabric }\end{array}$} & \multirow{3}{*}{$\begin{array}{c}\text { Yarn } \\
\text { diameter } \\
\text { in both } \\
\text { models } \\
(\mathrm{mm})\end{array}$} & \multirow{3}{*}{$\begin{array}{c}\text { Fiber } \\
\text { number in } \\
\text { multifiber } \\
\text { model }\end{array}$} & \multirow{3}{*}{$\begin{array}{c}\text { Fiber } \\
\text { diameter in } \\
\text { multifiber } \\
\text { model } \\
{[\mu \mathrm{m}]}\end{array}$} & \multicolumn{6}{|c|}{ Number of cells } \\
\hline & & & & & \multicolumn{3}{|c|}{ Monofiber model } & \multicolumn{3}{|c|}{ Multifiber model } \\
\hline & & & & & Fluid & Partial & All & Fluid & Partial & All \\
\hline \multirow{2}{*}{1} & Cotton & 0.25 & 122 & 15.2 & \multirow{2}{*}{21,184} & \multirow{2}{*}{13,318} & \multirow{2}{*}{34,502} & \multirow{2}{*}{41,349} & \multirow{2}{*}{23,769} & \multirow{2}{*}{65,118} \\
\hline & Cotton & 0.26 & 122 & 15.1 & & & & & & \\
\hline \multirow[b]{2}{*}{2} & Cotton & 0.25 & 122 & 15.3 & \multirow[b]{2}{*}{20,055} & \multirow[b]{2}{*}{12,608} & \multirow[b]{2}{*}{32,663} & \multirow[b]{2}{*}{39,146} & \multirow[b]{2}{*}{22,502} & \multirow[b]{2}{*}{61,648} \\
\hline & PP & 0.27 & 109 & 27.4 & & & & & & \\
\hline \multirow{2}{*}{3} & Cotton & 0.26 & 122 & 15.1 & \multirow{2}{*}{18,926} & \multirow{2}{*}{11,899} & \multirow{2}{*}{30,825} & \multirow{2}{*}{36,943} & \multirow{2}{*}{21,236} & \multirow{2}{*}{58,179} \\
\hline & PET & 0.30 & 96 & 26.2 & & & & & & \\
\hline \multirow[b]{2}{*}{4} & Cotton & 0.25 & 122 & 15.2 & \multirow[b]{2}{*}{19,447} & \multirow[b]{2}{*}{12,226} & & & & \\
\hline & PA & 0.28 & 102 & 23.4 & & & 31,673 & 37,960 & 21,820 & 59,780 \\
\hline & Bamboo & 0.22 & 86 & 24.4 & & & & & & \\
\hline 5 & PP & 0.27 & 109 & 27.3 & 16,929 & 10,644 & 27,573 & 33,046 & 18,995 & 52,041 \\
\hline & Bamboo & 0.22 & 86 & 24.3 & & & & & & \\
\hline 6 & PET & 0.30 & 96 & 26.2 & 15,801 & 9,934 & 25,735 & 30,842 & 17,728 & 48,571 \\
\hline & Bamboo & 0.22 & 86 & 24.3 & & & & & & \\
\hline 7 & PA & 0.28 & 102 & 23.1 & 16,321 & 10,262 & 26,583 & 31,859 & 18,313 & 50,172 \\
\hline & Viscose & 0.22 & 81 & 29.4 & & & & & & \\
\hline 8 & PP & 0.27 & 109 & 27.1 & 16,495 & 10,371 & 26,866 & 32,198 & 18,508 & 50,706 \\
\hline & Viscose & 0.22 & 81 & 29.3 & & & & & & \\
\hline y & PET & 0.30 & 96 & 26.2 & 15 & 9,661 & 28 & 95 & 42 & 231 \\
\hline & Viscose & 0.22 & 81 & 29.4 & & & & & & \\
\hline 10 & Viscose & 0.21 & 81 & 29.3 & 14,064 & 8,843 & 22,907 & 27,453 & 15,781 & 43,234 \\
\hline
\end{tabular}
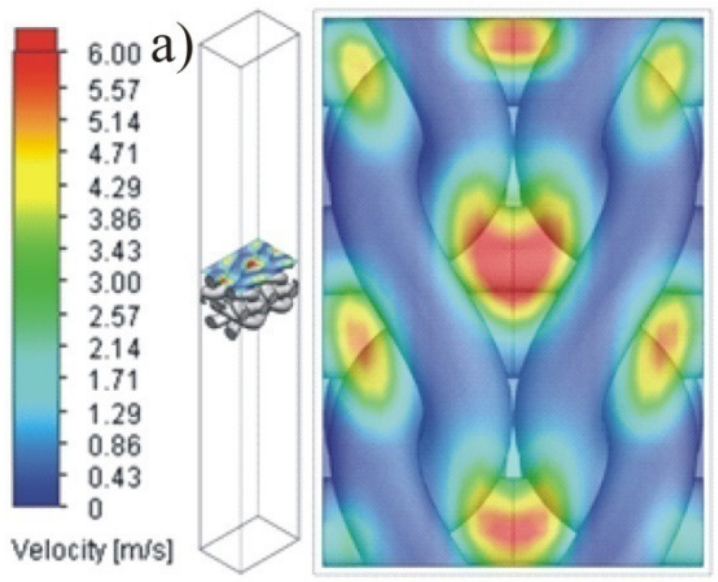

b)

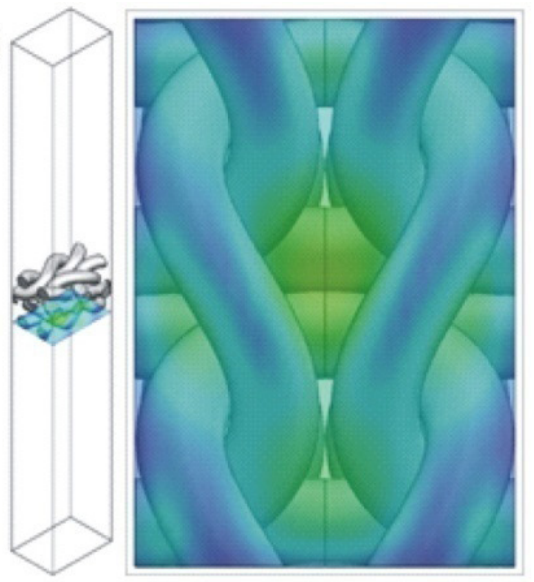

c)

Figure 9. Air velocity distributions on two horizontal planes: positioned directly above (a) and directly below (b) for the monofiber model; (c) visualization of the shape of the air flow lines. The color scale of air velocity is valid for all pictures $(a-c)$. 


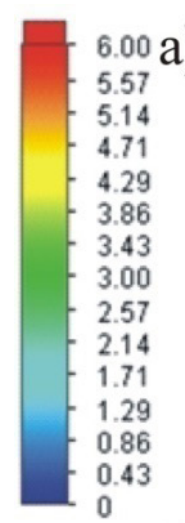

Velocity [m/s]

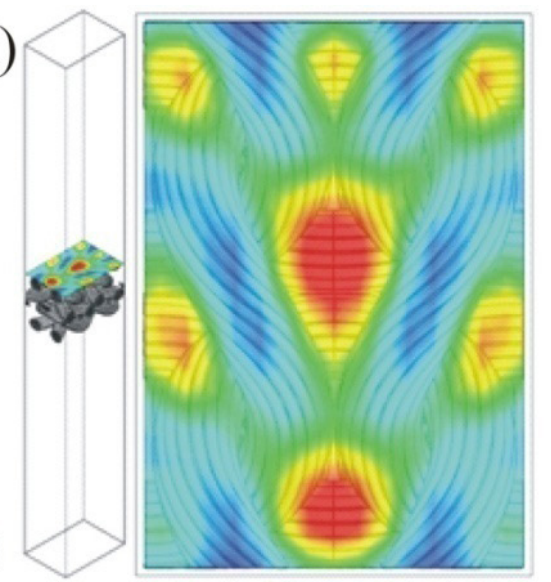

b)

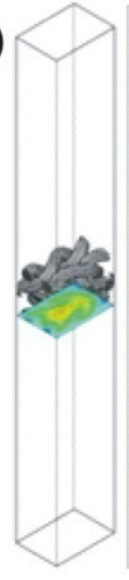

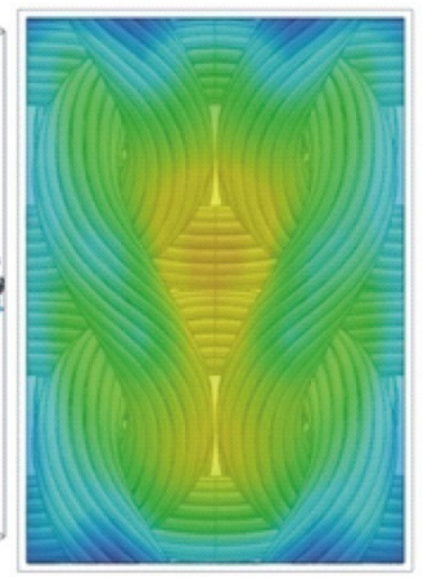

c)

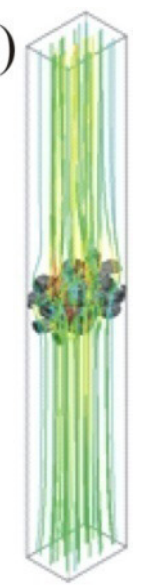

Figure 10. Air velocity distributions on two horizontal planes: positioned directly above (a) and directly below (b) for the multifiber model; (c) visualization of the shape of the air flow lines; the color scale of air velocity is valid for all pictures (a-c). The diameter of the fibers was intentionally increased in relation to the real sizes (Table 1) in order to improve the readability of the distribution.

but are shifted by half the width as one can see in Figure 11), all of the analyzed textiles were characterized by a very low optical porosity.

The difference in optical porosity between both models is small but noticeable (ranged from $1.01 \%$ to $1.05 \%$ in the monofiber model and from $1.36 \%$ to $2.11 \%$ in the multifiber model). It follows that in the monofiber model, the yarn is mapped as a monofilament with a cylindrical continuous surface along the entire length of the knitted fabric loop. In the multifiber model, the yarns were formed with single fibers surrounded by air. Let us consider the circular cross section of yarn in the multifiber model. The fibers located on the circumference of the cross section of the yarn determine its diameter. But there is also space present between them. This space affects the higher optical porosity compared to the monofiber model, in which there are no free spaces on the circumference of the cross section of the yarn (the line is continuous). A low value of the optical porosity for all of the knitted fabrics demonstrates that almost the entire air flow permeates through the textile by curved paths located between two layers of the knitted fabric.

In Figure 12, experimental and simulation results of air velocity for knitted fabrics (bar plot) and results of the optical porosity determined based on the monofiber model and multifiber model (scatter plot) were presented.

Simulations using both the models yielded comparable results as the experiment; however, the results obtained from the multifiber model were in better compliance with the measurements made using an air permeability tester. This repeated difference in the case of each analyzed knitted fabric may indicate a significant difference in the accuracy of mapping yarn in both the models. The free narrow spaces between the fibers in the multifiber model create additional channels for the air flow through the yarn. The fact that the simulated air velocity was lower than the experimental values for all knitted fabrics in both the monofiber and multifiber models was probably the result of the simplification of the cross-sectional shape of the yarn. In both the models, a circular cross section was assumed

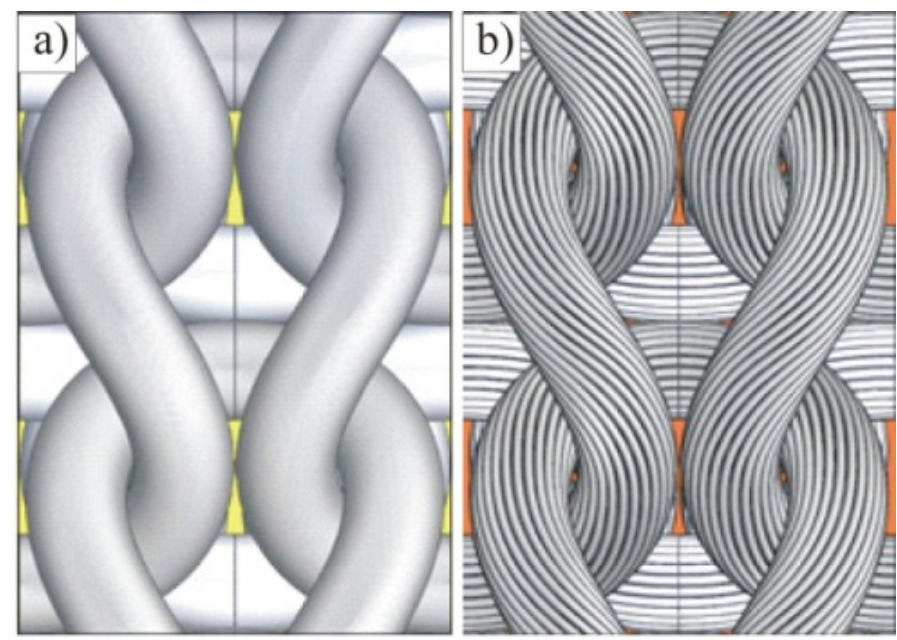

Figure 11. Visualization of the optical porosity for (a) monofiber model (yellow area) and (b) multifiber model (orange area); in multifiber model, the diameter of the fibers was intentionally increased in relation to the real sizes (Table 1 ) in order to improve readability of the scheme.

over the entire length of the loop. In the actual knitted fabrics, as a result of frictional forces between the adjacent loops, the yarn is flattened and its cross section is similar to the shape of an ellipse. This deformation of the cross section of the real yarn could lead to a reduction in the area of yarn surface in the direction perpendicular to the air stream and simultaneously to increase the area of yarn surface parallel to the air stream. This deformation may increase the optical porosity of real knitted fabrics and thus increase the air velocity. In the case of the monofiber model, the differences were in the range of $5.7 \%$ (Bamboo/PA) to $20.3 \%$ (Cotton/PP), while they were in the range of $4.1 \%$ (Bamboo/PA) to $14.8 \%$ (Cotton/PP) for the multifiber model (Figure 13). The simulation results obtained for both the models were also correlated with the experiment in case of air velocity differences measured on both sides of the knit (upper upper and lower layers). These differences result from the various parameters of the knitted fabric layers that were included in both the models (for the monofiber model: layer thickness, yarn diameter, and yarn length in single loop; for the multifiber model: layer thickness, yarn diameter, yarn length in single loop, fiber number, and fiber diameter). 


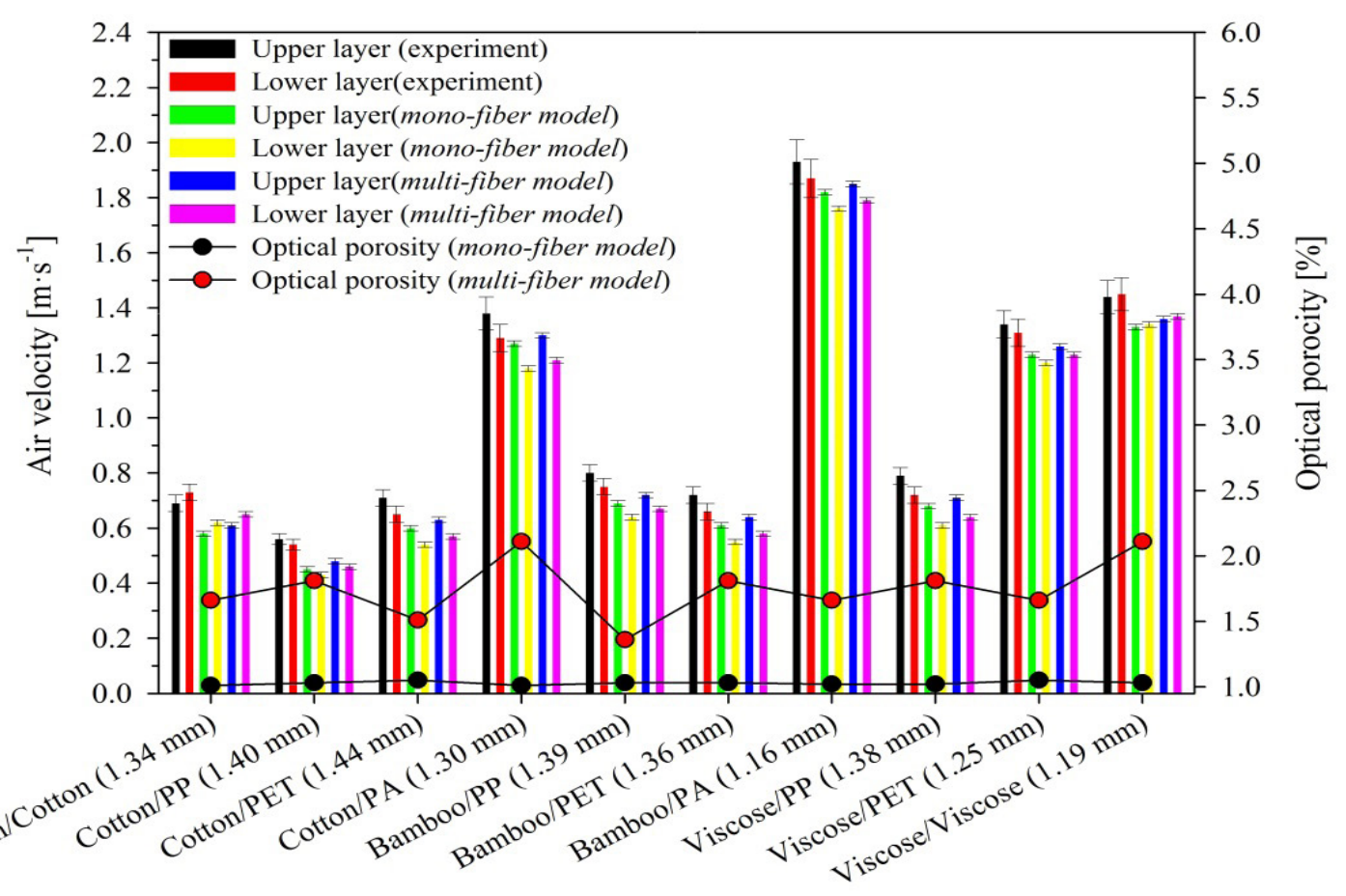

Figure 12. Bar plot: experimental and simulation results of air velocity for knitted fabrics; scatter plot: the results of the optical porosity determined based on the monofiber model and multifiber model (broken curves guide the eye).

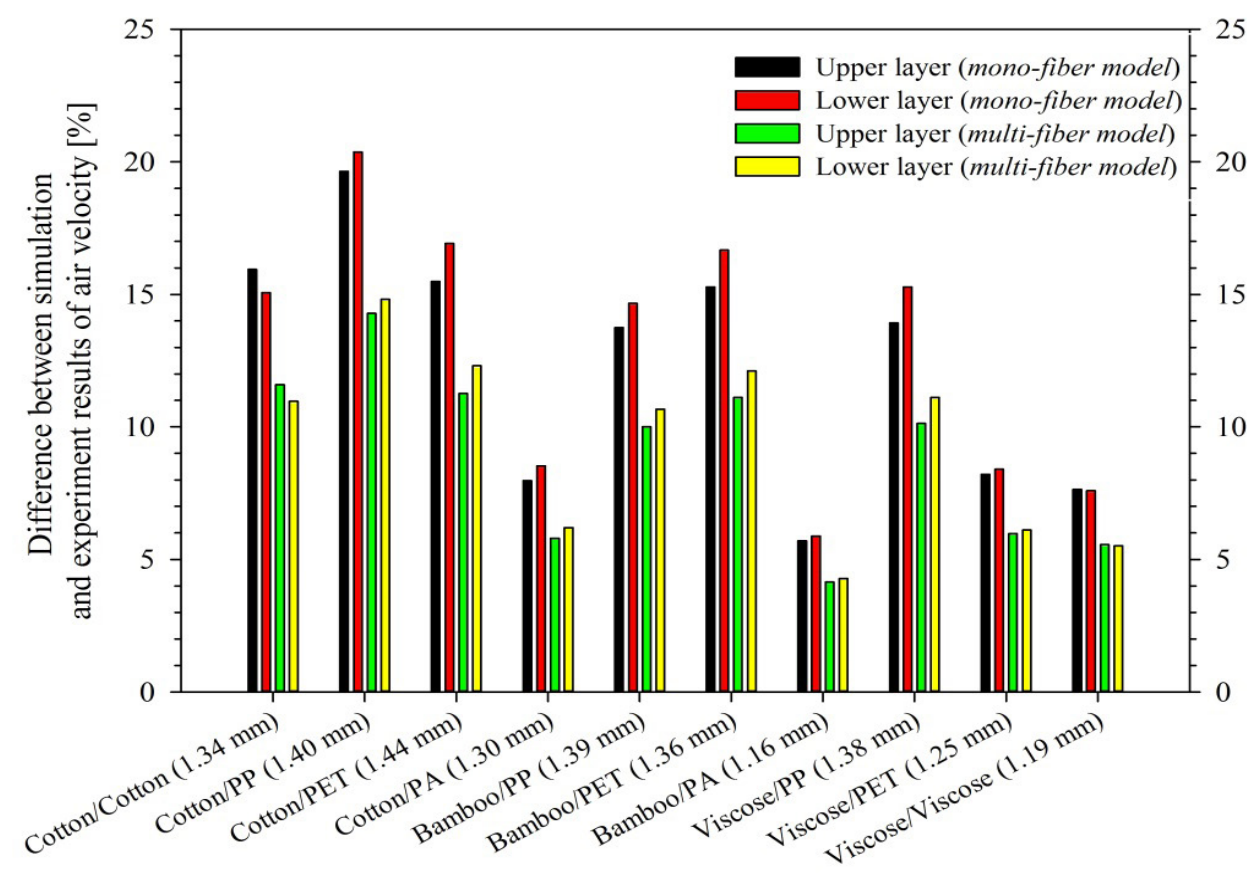

Figure 13. The percentage difference between simulation and experiment results of the air velocity

Moreover, in Figure 12, one can clearly see that in the multifiber model case, the porosity values are more varied relative to each other compared to the less complicated model, which may indicate that in addition to the mapping of the fiber, the number, size, and twist are important.
One of the reasons for the large differences observed in the three knitted fabrics containing cotton may be the fact that the assumption of a circular cross section for the cotton fiber was too big of a simplification compared to the chemical fibers. On the other hand, the differences in the results may also 
be related to the measurements of actual air velocity in the experiment. The complicated geometrical structure of a real knitted fabric is not perfectly periodic. As a result of mutual stresses, the yarns may be heterogeneous and the mass is not constant throughout each loop. It must also be assumed that the mutual distance of the two layers of knitted fabrics is not constant over the entire study area $\left(20 \mathrm{~cm}^{2}\right)$.

On the basis of the fact that the partial results of the experiment were described by a Gaussian distribution, for both the models (monofiber and multifiber), one-sample t-test was performed considering the null and alternative hypothesis as

$$
\begin{aligned}
& H_{0}: \bar{v}_{\exp }=v_{\text {sym }} \\
& H_{1}: \bar{v}_{\text {exp }} \neq v_{\text {sym }},
\end{aligned}
$$

where $\bar{v}_{\text {exp }}$ is the experimental average of air velocity of a given knitted fabric and $\bar{v}_{\text {sym }}$ is the simulated air velocity of a given knitted fabric. For all of the knitted fabrics, for both the monofiber and multifiber models, the test result indicates that at significance level $a=0.05$, the null hypothesis should be rejected (probability value, $p$-value was in the range of $0.041-$ 0.001 for the monofiber model and $0.047-0.003$ for the multifiber model) and the alternative hypothesis should be approved. This means that the differences between experimental and simulated values of the air velocity in case of some of tested knitted fabrics were greater than the statistical ones. This may be due to artifacts appearing in the structure of the knitted fabrics. Both the proposed models assumed perfectly periodic construction of knitted fabrics (each loop was the same size and shape). In fact, such a knitted fabric does not exist. For all knitted fabrics, the average air velocity calculated for the multifiber model was slightly higher in comparison to the monofiber model.
Another goal of the study was to examine the influence of the apparent density of the knitted fabric on air velocity determined experimentally and by simulation. As one can see in Figure 14, the relationship was decreasing.

The highest values of air velocity were obtained for fabrics with the lowest apparent density (Cotton/PA, cotton/PP, and Cotton/ PET), whereas the smallest ones were obtained for Cotton/ $\mathrm{PA}$ and Viscose/Viscose. Figure 15 shows the influence of the thickness of the knitted fabric on air velocity determined experimentally and by simulation. For most knitted fabrics, the average air velocity decreases with the thickness of the textile, but it is not a simple linear relationship.

The exceptions are three materials (Viscose/PP, Bamboo/PP, and Cotton/PET) for which the air velocity increases slightly. The reason for this could be differences in the other geometrical parameters, for example, the mutual distance of the two layers and/or optical porosity. The most air permeable material was the thinnest $(1.16 \mathrm{~mm})$ knitted fabric Bamboo/PA, having an optical porosity of $1.02 \%$ according to the monofiber model and $1.66 \%$ according to the multifiber model, whereas the least permeable material was Cotton/PP (thickness, $1.40 \mathrm{~mm}$ ), having an optical porosity of $1.03 \%$ according to the monofiber model and $1.81 \%$ according to the multifiber model.

The experimental values of air velocity ranged from 0.56 to $1.93 \mathrm{~m} \cdot \mathrm{s}^{-1}$ for the upper layer and from 0.54 to $1.89 \mathrm{~m} \cdot \mathrm{s}^{-1}$ for the lower layer. For the monofiber model, the obtained values ranged from 0.45 to $1.82 \mathrm{~m} \cdot \mathrm{s}^{-1}$ for the upper layer and from 0.43 to $1.86 \mathrm{~m} \cdot \mathrm{s}^{-1}$ for the lower layer, and for the multifiber model, the obtained values ranged from 0.48 to $1.85 \mathrm{~m} \cdot \mathrm{s}^{-1}$ for the upper layer and from 0.57 to $1.79 \mathrm{~m} \cdot \mathrm{s}^{-1}$ for the lower layer. The results of both the experiment and showed that almost

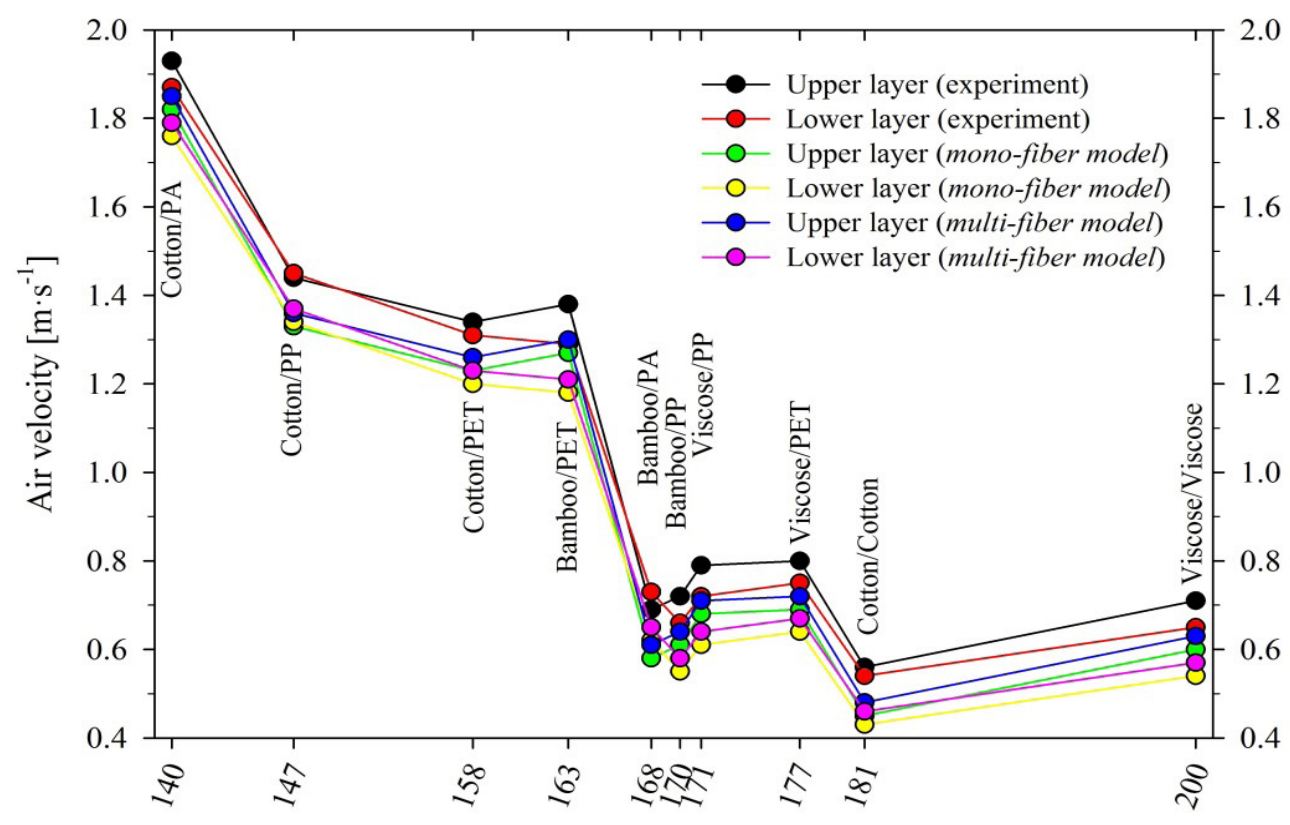

Apparent density $\left[\mathrm{kg} \cdot \mathrm{m}^{-3}\right]$

Figure 14. The influence of the apparent density of the knitted fabric on air velocity (determined experimentally and by simulation); broken curves guide the eye. 


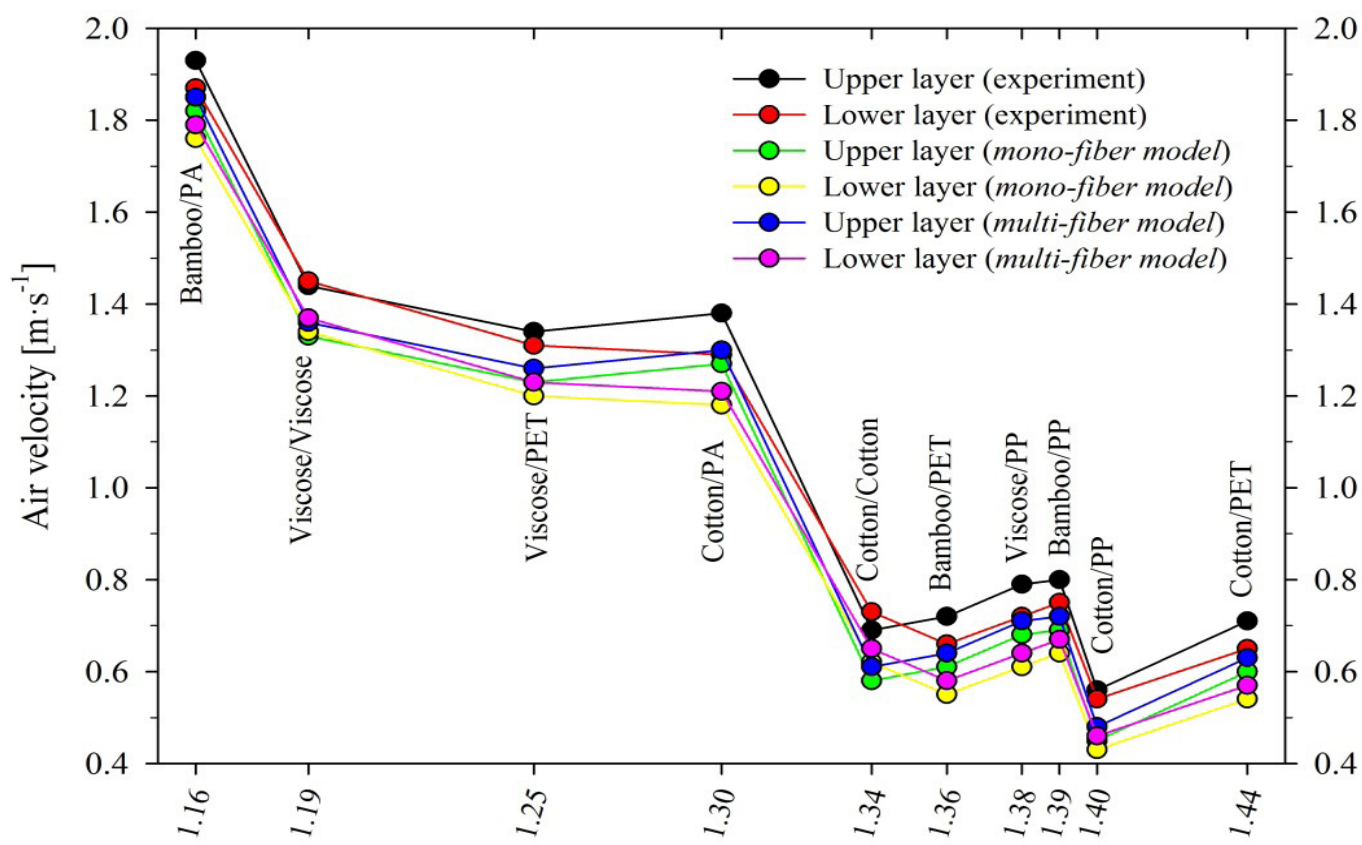

Knitted fabric thickness [mm]

Figure 15. The influence of the thickness of the knitted fabric on air velocity (determined experimentally and by simulation); broken curves guide the eye.

all fabrics were characterized by similar values of air velocity measured for both the layers.

\section{Conclusions}

In this article, the results of the modeling geometry of the doublelayer knitted fabrics to calculate the air permeability were obtained by means of simulations of the fluid flow phenomena. By using three-dimensional models of knitted fabrics, mapping the geometry in the microscale allowed the achievement of results correlating with the experimental outcomes. It is important to realize that even the more precise model, despite the use of geometrical parameters of real textiles, had a lot of simplification in relation to the complicated construction of real knits, which affects the final result of the simulation. On the other hand, the discrepancy between the results of the experiment and the simulations for the multifiber model indicates the need to correct this model, probably in the direction of increasing its similarity to the geometrical parameters of actual knitted fabrics. The presented results allows for drawing the following final conclusions:

1. The application of SolidWorks Flow Simulation and developed geometrical monofiber model of knitted fabric allows predicting the air permeability with the error on the level of $5.7-20.3 \%$ depending on the structure of the knitted fabric.

2. The application of SolidWorks Flow Simulation and developed geometrical multifiber model of knitted fabric allows predicting the air permeability with the error on the level of $4.1-14.8 \%$ depending on the structure of the knitted fabric.
3. The clear repetitive differences between the simulation performed on the monofiber model and the multifiber model indicate that the inclusion of fibers and free space between them is one of the important factors that determine the utility of the model for theoretical predictions of air permeability of the textiles.

4. The attempt to prove the effect of air permeability on the optical porosity by the application of the models has not produced a clear relationship that may indicate a stronger influence of other geometrical parameters of the knitted fabrics.

5. The presented models could be useful in predicting the physiological comfort of users of the designed and manufactured knitted fabrics.

\section{Acknowledgments}

These studies were partially financed from funds assigned from

1. National Science Centre (Poland) under the research project No. UMO-2011/03/B/ST8/06275 "Optimization of the structure of protective clothing for prematurely born infants with the use of original tools aiding the designing process"

2. 14-148-1-2117 statutory activity by the Lodz University of Technology, Department of Material and Commodity Sciences and Textile Metrology, Poland. 


\section{References}

[1] Ogulata R.T., Mavruz S. Investigation of Porosity and Air Permeability Values of Plain Knitted Fabrics. Fibres and Textiles in Eastern Europe 2010; 18, 5 (82): 71-75.

[2] Arumugam V., Mishra R., Militky J., Salacova J. Investigation on thermo-physiological and compression characteristics of weft-knitted $3 D$ spacer fabrics. The Journal of The Textile Institute, doi: 10.1080/00405000.2016.1220035

[3] Doczyova K., Glombikova V., Komarkova P. Application of Microtomography in Textile Metrology. Tekstilec 2014; 57(1): 4-11

[4] Mezarciöz Serin., Mezarciöz Serkan, Oğulata R. T. Prediction of air permeability of knitted fabrics by means of computational fluid dynamics. Tekstilvekonfeksiyon 2014; 24(2): 202-211

[5] Ogulata R.T. Air Permeability of Woven Fabrics. Journal of Textile and apparel. Technology Management 2006; 5: $1-10$.

[6] Havlová M. Air Permeability and Constructional Parameters of Woven Fabrics. Fibres and Textiles in Eastern Europe 2013; 21, 2(98): 84-89.

[7] Ghada Ahmad Mohamad. Comparative Study of Air Permeability of Polyester/Metallic Blended Woven Fabrics. Life Science Journal 2015; 12 (6): 78-82

[8] Angelova R.A. Determination of the pore size of woven structures through image analysis. Central European Journal of Engineering 2012; 2(1): 129-135

[9] Zupin Z., Hladnik A., Dimitrovski K. Prediction of one-layer woven fabrics air permeability using porosity parameters. Textile Research Journal 2011; 82(2): 117-128

[10] Polipowski M., Więcek P., Więcek B., Jasińska I. Study on Woven Fabric Structure Using 3D Computer Image Analysis for In-Depth Identification of Thread Channels. Fibres and Textiles in Eastern Europe 2015; 23, 2(110): 33-39.

[11] Strąkowska M., Więcek P., Polipowski M., Więcek B. Estimation of the Inter-Yarn Channel Inlet Diameter in Textile Materials Using Structured Light 3D MicroScanning. Fibres and Textiles in Eastern Europe 2016; 24, 6(120): 88-93. doi: 10.5604/12303666.1221741

[12] Havlová M. Detection of fabric structure irregularities using air permeability measurements. Journal of Engineered Fibers and Fabrics 2014; 9, 4:157-164
[13] Havlová M. Model of vertical porosity occurring in woven fabrics and its effect on air permeability. Fibres and Textiles in Eastern Europe 2014; 22, 4(106): 58-63

[14] Puszkarz A.K., Krucińska I. The study of knitted fabric thermal insulation using thermography and finite volume method. Textile Research Journal, 2017; 87(6): 643-656 doi:10.1177/0040517516635999

[15] Puszkarz A.K., Korycki R., Krucińska I. Simulations of heat transport phenomena in a three-dimensional model of knitted fabric. 2015; 16(3): 128-137 doi: 10.1515/aut2015-0042 @AUTEX

[16] Puszkarz A.K., Krucińska I. Study of multilayer clothing thermal insulation using thermography and the finite volume method. Fibres and Textiles in Eastern Europe 2016; 24 6(120): 129-137

[17] Lipp-Symonowicz B., Sztajnowski S., Wojciechowska D. New Commercial Fibres Called "Bamboo Fibres" - Their Structure and Properties. Fibres and Textiles in Eastern Europe 2011; 19 , 1 (84): 18-23

[18] Lipp-Symonowicz B., Sztajnowski S., Kulak A. IR spectroscopy as a possible method of analysing fibre structuresand theirchanges undervarious impacts."Infrared Radiation", book edited by Vasyl Morozhenko, ISBN 978953-51-0060-7, Shanghai: Intech, 2012; 1: 27-39

[19] Kowalski K., Janicka J., Massalska-Lipińska T., Nyka M. Impact of Raw Material combinations on the Biophysical Parameters and Underwear Microclimate of Two-Layer Knitted Materials. Fibres and Textiles in Eastern Europe 2010; 18, 5(82): 64-70.

[20] EN ISO 5084. Textiles - Determination of thickness of textiles and textile products

[21] EN 12127. Textiles - Fabrics - Determination of mass per unit area using small samples

[22] EN ISO 2060. Textiles - Yarn From Packages Determination Of Linear Density (mass Per Unit Length) - Skein method

[23] ISO 139. Textiles - Standard atmospheres for conditioning and testing

[24] EN ISO 9237. Textiles - Determination of the permeability of fabrics to air

[25] SolidWorks Flow Simulation - Technical Reference 2014

[26] Jeżowiecka-Kabsch K., Szewczyk H.. Mechanika płynów. Oficyna Wydawnicza Politechniki Wrocławskiej, Wrocław 2001 